\title{
Sobre laços, amor e discursos
}

\author{
About bonds, love and discourses
}

Sobre enlaces, amor y discursos

\section{Marina Vieira Espinoza* \\ Vera Lopes Besset}

\begin{abstract}
Resumo
Este artigo tem como objetivo discutir o tratamento dado ao mal-estar pela psicanálise no mundo contemporâneo, tendo em vista o modo como o sujeito se apresenta: submetido ao discurso do capitalista, desconectado do campo do Outro. Propomos uma manobra a mais no momento das entrevistas preliminares, visando a um enlaçamento entre analista e paciente, pela transferência, entendida como condição de possibilidade a todo tratamento analítico. Defendemos que, pela via do encontro com o discurso do analista e do amor de transferência, é possível promover a articulação do campo do sujeito com o campo do Outro, princípio de todo laço social, e permitir que o sujeito construa uma nova saída para lidar com o mal-estar, implicando-se em sua queixa e no sofrimento que relata.
\end{abstract}

Palavras-chave: Psicanálise; mal-estar; laço social; discurso analítico; transferência.

\begin{abstract}
This article discusses the treatment given to discontent by psychoanalysis in the contemporary world, considering the way the subject presents himself: submitted to capitalist discourse, detached from the Other's field. We propose a complementary maneuver during the preliminary interviews, aiming at a bond between analyst and patient through transference, understood as a condition for the possibility of all analytical treatment. We believe that, through the analyst's discourse and transference love, it is possible to promote the articulation between the subject's field and the Other's field, a principle of every social
\end{abstract}

\footnotetext{
Texto recebido em fevereiro de 2009 e aprovado para publicação em setembro de 2009.

Doutoranda e mestre pelo Programa de Pós-Graduação em Psicologia no Instituto de Psicologia/UFRJ, membro do Grupo de Pesquisa Clínica Psicanalítica (Clinp) - UFRJ/CNPq - UFRJ, psicóloga, e-mail: marinapvieira@yahoo.com.br.

* Doutora em Psicologia pela Universidade Paris V, professora do Programa de Pós-graduação em Psicologia do Instituto de Psicologia da UFRJ, pesquisadora da Associação Universitária de Pesquisa em Psicopatologia Fundamental; coordenadora do Grupo de Pesquisa Clínica Psicanalítica (Clinp) - UFRJ/CNPq; Bolsita de Produtividade em Pesquisa-CNPq, e-mail: besset@terra.com.br.
} 
bond, and to allow the subject to envisage a new way to deal with his discontent, revealing himself in his complaint and in the suffering that he describes.

Key words: Psychoanalysis; discontent; social bond; analytic discourse; transference.

\section{Resumen}

Este artículo tiene como objetivo discutir el tratamiento dado al malestar por el psicoanálisis en épocas contemporáneas, la manera como el sujeto se presenta: sometido al discurso capitalista, separado del campo del Otro. Proponemos una maniobra complementaria en el momento de las entrevistas preliminares, teniendo como objetivo un acoplamiento entre el analista y el paciente, a través de la transferencia, entendida como condición ¿de la posibilidad? a todo el tratamiento analítico. Defendemos que a través del encuentro con el discurso analítico y del amor de la transferencia es posible promover la articulación del campo del sujeto con el campo del Otro, el principio de todo el enlace social, y permitir al sujeto la construcción de una nueva salida que se ocupe de su malestar, implicándose en su queja y en el sufrimiento que él relata.

Palabras claves: Psicoanálisis; malestar; enlace social; discurso analítico; transferência.

\section{Considerações preliminares}

ânico, depressão, ansiedade, fobia e stress, formas de apresentação do sofrimento nas queixas dos sujeitos que buscam um tratamento, denominaçôes atuais para o que Freud (1930) chamou de mal-estar na cultura. Em seu texto sobre o tema, escrito em 1929, o autor afirma que alcançar e manter a felicidade, propósito da vida dos seres humanos, é um programa irrealizável. Isso porque a felicidade corresponderia à satisfação imediata de necessidades: "Se uma situação ansiada pelo princípio do prazer perdura, em nenhum caso se obtém mais do que um ligeiro sentimento de bem estar; estamos organizados de tal modo que só podemos gozar com intensidade o contraste e muito pouco com o estado" (Freud 1986/1930 [1929], p. 76) (tradução nossa). Segundo ele, seriam três as fontes privilegiadas de sofrimento para o homem: o próprio corpo, o mundo externo e o relacionamento com os outros (Freud, 1986/1930 [1929], p. 76). Resume, então, o mal-estar ao qual se refere:

A vida, como nos é imposta, resulta árdua: nos traz fartas dores, desenganos, tarefas insolúveis. Para suportá-la, não podemos 
prescindir de calmantes. Eles existem, talvez, de três classes: poderosas distrações substitutivas, que nos fazem amenizar um pouco nossa miséria; satisfações substitutivas, que a reduzem; e substâncias entorpecentes que nos tornam insensíveis a elas (Freud, 1986/1930) (tradução nossa).

Em contraponto a isso, as diretrizes de nossa cultura, radicalizando os princípios da modernidade (Lipovetsky, 2004), indicam que os sujeitos devem ser felizes e completos. Assim, devem eliminar os fatores que causam desconforto e os desviam da rota da plenitude. Nesse contexto, inúmeros são os objetos elevados ao status de portadores da solução contra qualquer tipo de sofrimento. $\mathrm{O}$ aumento da oferta desses produtos é fruto da exaltação do prazer a qualquer custo, em consonância com a lógica da sociedade de consumo, que incentiva a aquisição e o descarte de bens (Bauman, 2003; Miller, 2004). No entanto, essa "técnica" fracassa em sua função de garantir o bem-estar e, desse modo, a felicidade. Isso porque, invariavelmente, o objeto escolhido para tamponar a falta não sustenta essa função e o sofrimento retorna. No melhor dos casos, sob a forma de sintoma. Sendo assim, registram-se várias propostas de tratamento. Nesse contexto, observa-se uma diminuição no interesse do sujeito em deixar-se interpelar por seu sofrimento, mostrando-se cada vez mais acomodado em uma posição de vítima ou de objeto.

As novidades produzidas pela ciência são difundidas pela rede mundial da internet: diversos tipos de terapia, remédios, livros de autoajuda. Nesse mesmo movimento, vemos o incremento da avaliação e dos protocolos como forma de universalizar e padronizar a partir da média, que acaba por excluir o que há de particular em cada sujeito (Miller, 2004; 2005; Miller; Milner, 2006). Com a proliferação dos diagnósticos, que acabam funcionando como rótulos, tudo pode ser justificado, pois tem uma causa e se resume no "transtorno", na "doença". Quando a sintonia de seu quadro sintomático é abalada, por vezes, um sujeito procura um tratamento. Em geral, buscando a restituição de uma situação anterior, de harmonia com seu sintoma. Isso, a partir de uma solução que não demande muito investimento, seja de tempo, de renúncia ou de elaboração. Sobre isso nos diz Palomera:

O sujeito não ignora o mal-estar do sintoma como resposta desprazeroza; o que ignora do que não quer saber é a verdade que responde ao sintoma, o ser de verdade que sobre ele, como sujeito, traz o sintoma à luz do dia (Palomera, 2004, p. 3) (tradução nossa).

A proposta da psicanálise tem como condição uma abertura do sujeito à responsabilização por seu sofrimento. Imersa no cenário dos tempos 
hipermodernos, ela trabalha, entretanto, a partir de uma lógica diversa à do tamponamento ou do apaziguamento da dor de existir (Brousse, 2003, p. 69). Nela se trata de lidar com o sofrimento de maneira distinta, pois, no lugar dos objetos de consumo ou de promessas milagrosas de autocontrole e felicidade, um psicanalista oferece sua escuta. Nesse sentido, é a partir do acolhimento do sintoma que é possível à psicanálise operar. Sobre isso, Palomera assinala que o próprio sintoma aponta sua dimensão de verdade. Assim, a despeito de o sujeito não querer saber a verdade do que ele é em seu sintoma, "conforme o sintoma o divide, e como está dividido sem saber disso que há nele e que se manifesta no estranho do sintoma, vê-se induzido a saber" (Palomera, 2004, p. 3) (tradução nossa). O que do sintoma aparece como estranho, é o que Lacan assinala como sendo o seu sentido:

O sentido do sintoma não é aquele com o qual a gente o nutre para sua proliferação ou extinção, o sentido do sintoma é o real, o real que se coloca como uma pedra no caminho para impedir que as coisas andem no sentido de dar conta delas mesmas de maneira satisfatória - satisfatória ao menos para o mestre, o que não quer dizer que o escravo não sofra com isso, muito pelo contrário (Lacan, 1975, p. 181) (tradução nossa).

Para que a oferta da psicanálise seja acolhida, no particular da demanda de cada sujeito, é necessário se valer da confiança, isto é, da transferência (Breuer; Freud, 1893-1895). Todavia, atualmente, quando os vínculos apresentam-se frágeis e a relação com os objetos se caracteriza pelo predomínio do uso em detrimento do vínculo, quais as condiçôes para que um tratamento analítico possa se dar? Nas palavras de outro autor contemporâneo, temos: "Como levar hoje o sujeito do sintoma a abrirse à dimensão do Outro da palavra e da linguagem, a interessar-se assim no deciframento da sua mensagem inconsciente?" (Bassols, 2004, p. 1) (tradução nossa). Essas são questôes que norteiam as reflexões deste texto, no qual nos valemos de algumas ferramentas teórico-metodológicas, notadamente, dos quatro discursos formulados por Lacan (1969-1970); igualmente, entre elas incluímos aquele que seria o quinto, o discurso do capitalista (Lacan, 1972), que nos servirá para pensar a configuração dos laços em nossa época.

\section{Laços e discursos}

É com a formalização dos discursos que Lacan aborda as fontes de malestar incontornáveis no caminho do homem em sua busca de felicidade. Para 
tanto, parte do primado do falo postulado por Freud (Freud, 1989 [1923]) e chama atenção para seu correlato de "não relação" entre os sexos (Lacan, 1975), como nomeia a consequência psíquica da ausência da simbolização do sexo feminino. Tomando como premissa essa "não-relação", propõe quatro modalidades de discurso (Lacan, 1991), que organizam os laços entre o sujeito, o Outro, o saber e o objeto. $\mathrm{Na}$ estrutura desses discursos, existem quatro lugares fixos e organizados de modo distinto. São fixos porque "todo e qualquer discurso é sempre movido por uma verdade, sua mola propulsora, sobre a qual está assentado um agente, que se dirige a um outro, a fim de obter deste uma produção" (Jorge, 2002, p. 26). Retomamos, a seguir, as quatro letras e os quatro lugares configurados em discursos por Lacan (1991, p. 31):

\section{Matema I}

No qual S1 designa o "significante-mestre", S2 o saber, \$ o sujeito e $a$ o gozo; e os lugares são, primeiro, o do agente, acima da primeira barra, segundo, o do trabalho, acima da segunda barra, da verdade, embaixo à esquerda e, por fim, o da produção, embaixo, à direita.

O princípio de todo laço social é a articulação do campo do sujeito com o campo do Outro. Essa articulação se desenha de um modo específico em cada um dos discursos. Assim, na estrutura dos discursos, podemos distinguir dois campos diversos e, a partir da posição da seta, podemos ver a articulação do lugar do agente com o lugar do outro.

\section{Matema II ${ }^{1}$}

Entre esses quatro discursos, o discurso do psicanalista, inaugurado por Freud e formalizado por Lacan (1969-1970), representou uma nova forma de laço social. Uma de suas características é ser o avesso do discurso do mestre. Ao oferecer uma escuta ao sofrimento de suas pacientes histéricas, Freud fez uma aposta ao supor que o material que elas traziam pela fala continha um saber. Desse modo, ao construir a psicanálise, não se colocou na posição do mestre, daquele que sabe previamente, inaugurando uma posição inédita.

Todavia, é o quinto discurso que nos ajuda a apreender o contexto no qual se insere a clínica atual. $\mathrm{O}$ discurso do capitalista pode ser considerado como 
o discurso do mestre moderno ${ }^{2}$, aquele que orienta as relações na atualidade. Similar ao discurso do mestre, traz uma distinção, a inversão na primeira parte da estrutura: o binômio inicial é invertido e o \$ está sobre o S1. O sujeito toma o lugar de agente, e o significante-mestre encontra-se no lugar da verdade. Sobre isso, Horne (2007, p. 62) afirma: "O \$ demanda ao S1 objetos de gozo. O S1 ordena ao saber da ciência sua produção e ofertas desenfreadas". Segundo essa formulação, esse quinto discurso é aquele que não faz laço social, principal característica que o distingue dos demais (Jorge, 2002, p. 32).

\section{Matema III}

Nesse discurso, o sujeito não se dirige a um outro, mas sim ao objeto. No discurso do mestre moderno, a ligação entre o campo do sujeito e o campo do Outro está enfraquecida. Notamos, a partir do matema, que a ligação entre os binômios relativos ao campo do sujeito e ao campo do Outro não ocorre pelo lugar do agente em direção ao outro. A ligação se dá a partir do lugar da verdade (S1) em direção ao lugar do outro (S2). Temos, então, o sujeito como agente, mas atuando em função dos significantes mestres que se encontram sob a barra, sem se dar conta disso.

No discurso do capitalista, há uma predominância da relação do sujeito com o objeto, com a evidente promessa de acabar com o mal-estar. Por esse motivo, afirmamos que ele não favorece o laço social, ao contrário dos demais discursos que estabelecem a articulação com o campo do Outro. Em função disso, Lacan pode afirmar que "Toda a ordem, todo o discurso que é conectado no capitalismo, deixa do lado o que nós chamaremos simplesmente as coisas do amor, meus amigos. Veem isso, é? Não é pouca coisa!"3 (Lacan, 1971-1972). Sendo assim, retomamos nossa questão: considerando-se que no, contexto atual, um sujeito chega ao consultório inserido no discurso capitalista, que alternativa temos a oferecer tendo a psicanálise como ferramenta clínica? Isso, partindo-se do princípio de que é necessário, embora não suficiente, o estabelecimento de um laço, transferência entre analista e paciente.

Seguindo a trilha dos escritos de Freud e do ensino de Lacan, entendemos que a via para o tratamento analítico é o amor de transferência. Tomamos esse fenômeno como o articulador que permitirá ao sujeito construir um novo modo de relação com o seu sofrimento. Assim, se para Lacan (1973, p. 555), "a transferência é amor", esse se especifica por ser "... amor que se dirige ao saber".

\footnotetext{
Quinto discurso, cujo matema foi exibido por Lacan em uma conferência em Milão, em maio de 1972. No entanto, no Seminário, livro 17: o avesso da psicanálise, o autor menciona tal discurso, sem propor uma fórmula para este (p. 103).

3 Tradução nossa. Retirado do $C D-R O M$ da obra de Jacques Lacan.
} 


\section{O amor e a transferência}

Ao longo de toda a sua obra, Lacan enfatiza a importância do fenômeno do amor na experiência de análise. Afirma que, no tratamento analítico, nós nos ocupamos das coisas do amor (Lacan, 1960-1961). Retoma essa ideia alguns anos mais tarde (1972-1973), dizendo: "Na análise, só lidamos com isso, e não é por uma outra via que ela opera” (Lacan, 1972-1973, p. 91). Confirma, apontando que "Falar de amor, com efeito, não se faz outra coisa no discurso analítico" (Lacan, 1972-1973, p. 112). Nesse contexto, é possível considerar o amor como um instrumento para produzir um saber sobre a verdade (SolanoSuarez, 2006). O amor se caracteriza pela crença de que, da relação entre dois, faz-se Um (Solano-Suarez, 2006). Por essa ilusão, podemos pensar na vinculação do sujeito com o Outro, o objeto amado.

Acreditar que o parceiro do amor pode dizer alguma coisa é amálo. Do mesmo modo, graças à transferência, pode-se acreditar que o sintoma quer dizer alguma coisa, o correlato à transferência. "Acreditar nisso" é próprio da transferência. A transferência é uma crença que se fundamenta no amor. Acreditar que o sintoma pode dizer algo é a condição de sua decifração (Solano-Suarez, 2005, p. 56).

No final de seu ensino, Lacan concebe o amor como o que, na experiência analítica, se apresenta de saída. No Seminário 20, o autor afirma: "Aquele a quem eu suponho um saber, eu o amo" (Lacan, 1972-1973, p. 91). Ao mesmo tempo, conceitua os sujeitos como dispersos, disjuntos, sem ligação uns com os outros. De fato, o que se observa no contemporâneo é que o sujeito não remete uma pergunta ao Outro com o qual seu enlaçamento encontrase fragilizado. Assim, ao abrir um espaço de oferta, ao convidar o sujeito a falar, o analista estimula um enlaçamento possível. É o que acreditamos ser necessário para o estabelecimento da relação simbólica, condição para a ligação dos um-sozinhos (Miller, 2005).

Frente ao valor de gozo do sintoma, o desafio que se apresenta é fazer valer o seu valor de sentido, promessa de saber que permite a instauração do dispositivo. Nesse caso, é possível afirmar que a política da psicanálise seria a politica do sintoma (Besset, 2004, p. 68), que se explicitaria assim: abrir a divisão do inconsciente e permitir fazer-se receptor de seu sintoma como mensagem a decifrar. Esse trabalho preliminar, digamos, seria um passo preliminar necessário em grande número de casos, considerando as coordenadas culturais da subjetividade de nossa época, que assinalamos neste texto. Em relação a isso, Miller (2007) assinala que, atualmente, verificamos a existência de um inconsciente real, em contraste com o inconsciente transferencial, 
entendido como o inconsciente freudiano. $\mathrm{O}$ inconsciente real seria aquele que não produz sentido, não interpreta. Exterior ao sujeito suposto saber, ele apresentar-se-ia como um limite à psicanálise.

Entretanto, a possibilidade de supor um sentido a seu sintoma faz ex-sistir um Outro a quem endereçar uma pergunta, forjada a partir de sua queixa. É o discurso analítico que nos permite trabalhar com base na fala e estabelecer a ligação entre analista e paciente. Para tal, é necessário fazer existir a relação simbólica, $S 1 \rightarrow S 2$, fazer existir o inconsciente como saber. E "o que faz existir o inconsciente como saber é o amor" (Miller, 2005, p. 18). A relação entre S1 e S2 encontra-se no algoritmo da transferência. A partir desse algoritmo proposto por Lacan (1967), Miller (2007) traz o S1 como o significante da transferência em seu laço com S2, significante qualquer do analista. Para ele, essa fórmula demonstra, em termos de significantes, a relação que condiciona a operação analítica. Fruto do laço entre S1-S2, em posição de significado, está o sujeito suposto saber, sob a barra.

\section{Esquema I}

"Disso resulta um sujeito. O sujeito resulta do estabelecimento dessa conexão" (Miller, 2007, p. 5). Sendo assim, essa articulação é necessária para que haja um efeito de sentido que mobilize os significantes do inconsciente. Esse estímulo à fala do paciente também desperta o amor de transferência, já que o sujeito sente-se faltoso por conta da castração. Essa condição de "malfeito", como diz Miller (1987[1997], p. 233), caracteriza um estado de reivindicação que move o sujeito. $\mathrm{O}$ analista, então, é tomado como o portador de um objeto precioso, capaz de promover a completude. Nesse caso, o sujeito quer tornar-se pleno e espera receber do analista o bem que lhe falta. É o jogo, na experiência analítica, entre o érastès e o érménos (Lacan, 1960-1961), o amante e o amado.

Essa crença inerente ao amor, a de que o outro possui o que falta ao sujeito, atribui ao analista o lugar de portador do saber sobre o sofrimento. $\mathrm{O}$ sujeito é, então, enlaçado na crença de que há algo a ser desvelado e que o analista sabe o que é. Seu sofrimento passa a ser portador de uma mensagem e o sintoma ganha sentido. Sustentar-se nesse lugar de quem sabe, essa seria a impostura do analista (Lacan, 1960-1961). O analista, que intervém com base no discurso analítico, ao convidar o sujeito a falar, permite a produção da relação simbólica. Como efeito, esse convite instaura a dimensão do sujeito suposto saber, remetendo o sujeito a um saber sobre seu inconsciente. Dessa maneira, aquele sofrimento apresentado despido de qualquer sentido, de 
qualquer pergunta, no momento de chegada do paciente ao tratamento, ganha contorno e abre uma nova perspectiva de saída. É essa suposição que enlaça o sujeito, seu inconsciente e o analista. Entendemos, com Lacan (1953), que um significante sozinho não produz sentido. Assim, o surgimento do sujeito suposto saber se dá a partir do estabelecimento da relação simbólica. É da associação com um, ou mais significantes, por um movimento de retroação, que um significado pode ser vislumbrado. Dessa maneira, o sentido só pode ser dado a posteriori.

A cadeia significante também não pode ser considerada como produtora de um sentido único, já que cada nova articulação significante produz um novo efeito de sentido. $\mathrm{Na}$ análise, como produto do trabalho do analisante, essas articulações significantes se refazem de acordo com o percurso do sujeito. É essa característica do inconsciente estruturado como linguagem que permite ao sujeito contar a sua história de maneira diferente. As produções oriundas dessas articulaçõos significantes são consideradas verdades para o sujeito, mas sem se transformar em uma verdade engessada. É essa característica que permite o deslizamento do sujeito entre os discursos. Essa articulação entre significantes como produtora de uma verdade pode ser esquematicamente observada desta forma:

\section{Esquema II}

Entendemos que o sujeito suposto saber é produzido na experiência analítica, podendo ser alocado no lugar da verdade. Aqui, o algoritmo da transferência nos serve de orientação para explicitar o SSS como efeito da relação simbólica. Para Brodsky (2000), no começo da análise não está o inconsciente como saber, assim, o sujeito suposto saber é a significação de saber produzida pelo tratamento. Desse modo, a psicanálise cria o saber como referência do discurso; é como se a psicanálise criasse um artifício para transforma, o estatuto do inconsciente e poder tratá-lo. Assim, é possível pensar, tal como Solano-Suarez (2005), que tanto o sujeito como efeito quanto a suposição de saber são consequências do amor.

\section{O a mais do tratamento preliminar: do discurso capitalista ao discurso do mestre}

Recorrendo a Lacan, em seus fundamentos, encontramos a formulação da experiência analítica como uma "experiência de discurso" (Lacan, 19691970, p. 16). Solano-Suarez (2005, p. 51) propõe o tratamento analítico como 
um "dispositivo de discurso", que toma a fala como instrumento e obtém a transferência como resultado. Essas formulações tomam a castração, fundadora do sujeito e responsável pela falta originária, como o fator motivador da fala e da produção do laço entre analista e paciente.

Trabalhando a partir da neurose, o que caracteriza a condição subjetiva é precisamente estar circulando entre os discursos. Em contrapartida, entendemos que, muitas vezes, a demanda que recebemos nos consultórios e instituições é de um sujeito submetido ao discurso capitalista, em busca de um bem que lhe apazigue o sofrimento ou o elimine, sem precisar refletir sobre a sua participação na situação que incomoda.

Como visto anteriormente, no discurso capitalista, a ligação do campo do sujeito com o campo do Outro está abalada. Dessa maneira, entendemos que o sujeito alojado nesse discurso, ao procurar por tratamento, não está interessado em refletir ou assumir uma postura mais ativa em relação ao seu sofrimento, implicando-se, lançando uma pergunta sobre o que incomoda. Geralmente esse sujeito busca uma solução, a palavra do analista como o remédio usado para tentar eliminar o mal-estar ou como a última novidade lançada pela moda que o tornará igual ao resto da comunidade na qual está inserido.

A psicanálise não trabalha nesse viés, mas tem meios de atuar a partir dele. $\mathrm{O}$ analista acolhe a demanda de alívio do paciente, mas não responde a ela. O objetivo inicial torna-se o de estabelecer a transferência, permitindo o deslocamento do sujeito alojado no discurso capitalista para o discurso do mestre. Essa é uma transformação importante para fazer valer a relação simbólica $(\mathrm{S} 1 \rightarrow \mathrm{S} 2)$. Nesse contexto, ao trabalharmos com o sujeito, produto da castração, há uma brecha para que o laço se dê. Os objetos não sustentam a função de tamponamento dessa falha fundamental, e essa hiância nos permite enlaçar o sujeito pela via do amor de transferência.

Baseado no último ensino de Lacan (1972-1973), Miller (2005, p. 42) nos diz que o amor é capaz de fazer a ligação dos "um-sozinho", sujeitos tal como se encontram no contemporâneo. Essa é uma característica específica daqueles alojados no discurso capitalista.

É o único meio de estabelecer uma relação entre $S 1$ e S2, porque no estado primário têm-se uns disjuntos, dispersos. Então, uma psicanálise demanda amar seu inconsciente para fazer existir não a relação sexual, mas a relação simbólica (Miller, 2005, p. 18).

Nesse contexto, para que um tratamento analítico tenha lugar, é necessário um trabalho preliminar que permita a mudança do discurso capitalista para o 
discurso do mestre, entendido como o discurso do inconsciente, para que se instaure a relação simbólica $(\mathrm{S} 1 \rightarrow \mathrm{S} 2)$. Ao alojar-se nesse outro discurso, o fruto da relação entre S1 e S2 é a produção de um sujeito. Essa modificação é possível pelo encontro do paciente com o discurso do analista, como aponta Lacan no trecho seguinte:

Chegamos enfim ao nível do discurso do analista. Naturalmente, ninguém assinalou - é muito curioso que o que ele produz nada mais seja do que o discurso do mestre, já que $S 1$ é o que vem no lugar da produção. E como eu dizia da última vez, quando deixei Vincennes, talvez seja do discurso do analista, se fizermos esses três quartos de giro, que possa surgir um outro estilo de significante-mestre (Lacan, 1969-1970, p. 168).

Com base no que Lacan nos apresenta, podemos supor que o discurso analítico produz o discurso do mestre. Isso porque Lacan ressalta que a produção daquele discurso é o $S 1$, agente no discurso da mestria. E que, se partirmos do lugar do S1 no discurso analítico e fizermos três quartos de giro, poderemos trabalhar com o sujeito alojado no discurso da histeria. Mudanças de discurso possibilitadas pelo encontro com o laço específico da psicanálise.

A virada do discurso capitalista para o discurso do mestre é possível porque o analista estimula a fala do sujeito. Longe de oferecer uma resposta que vá funcionar como apaziguador, o analista deixará uma brecha para que o sujeito possa desenrolar a queixa que o leva a buscar tratamento. Essa especificidade do discurso analítico nos permite sustentar que, ao fazer surgir o significante-mestre em outro lugar, na posição do trabalho no discurso da histeria, permitirá ao sujeito contar a sua história de forma diferente e, assim, construir uma saída nova para seu sofrimento.

As características do laço que rege a prática do analista abrem espaço para que um caminho novo possa ser construído. Ao permitir que haja o deslocamento do sujeito para outro discurso, vislumbra-se a possibilidade de novas respostas. Então, sair do discurso capitalista e passar pelo discurso do mestre torna-se uma etapa fundamental para a instalação da experiência analítica. Sobre isso, Lacan, em seu Seminário 17, nos diz: "A prática analítica é propriamente iniciada por esse discurso do mestre" (Lacan, 19691970, p. 144). Daí a importância desse a mais que propomos ao tratamento preliminar. Nos esquemas a seguir, podemos observar a mudança de que se trata nesta proposta. Destacamos, com especial ênfase no discurso do mestre, a relação de $S 1$ com S2, presente na parte superior do matema: 


\section{Esquema IV}

No discurso do mestre, a articulação de $S 1$ com $S 2$ produz a relação simbólica e o laço social porque liga o campo do sujeito (lugar do agente) com o campo do Outro (lugar do outro, do trabalho). Diversamente da articulação que encontramos no discurso capitalista, em que a ligação não ocorre do lugar do agente.

A relação fundamental de $S 1$ com $S 2$, presente na parte superior do matema do discurso do mestre, tem como efeito a produção de um sujeito, caso haja algum fator que desencadeie esse processo de associação. Consideramos que esse fator é a própria castração, que motiva a fala do paciente. $\mathrm{O}$ analista, ao dar ênfase à falta e não à completude, permite o estabelecimento dessa relação simbólica, considerada a primeira relação de saber. Para Lacan (1969-1970), o que descobrimos na experiência de qualquer análise é da ordem do saber e, em sua origem, o saber está reduzido à articulação significante. Lembramos que trabalhamos com a noção de sujeito do significante, que só pode ser representado entre dois significantes (Lacan, 1969-1970, p. 48).

O saber na experiência não é o saber do conhecimento ou da representação. "Trata-se precisamente de algo que liga, em uma relação de razão, um significante S1 a outro significante S2" (Lacan, 1969-1970, p. 28). Essa relação de razão é encontrada no discurso da histeria. Tendo em vista que é dessa relação de razão que se trata na experiência e que ela está presente no discurso da histeria, devemos tomá-la como norte na direção do tratamento. Lacan (1969-1970) considera que todo analisando encontra-se no discurso histérico e que o analista busca trazer para a cena principal, tornando-se objeto para seu analisante, a posição deste, de sujeito barrado. Mas, para tal, é preciso avançar em um trabalho preliminar.

Evidentemente, o estabelecimento da experiência analítica não ocorre desde a chegada do paciente no consultório. Existe esse momento de acolhimento e de instalação da transferência, mas o trabalho tem uma direção clara, nos esclarece Lacan (1969-1970, p. 31): "O que o analista institui como experiência analítica pode-se dizer simplesmente - é a histerização do discurso. Em outras palavras, é a introdução artificial, mediante condições artificiais, do discurso da histérica [...]". Entendemos que as condições artificiais às quais o autor faz referência são aquelas relativas à transferência. $\mathrm{O}$ período inicial do tratamento analítico, das entrevistas preliminares, propiciará uma mudança de posição subjetiva, em que a transferência e a demanda do sujeito adquirem outro estatuto. 


\section{Conclusão}

Ao tomarmos o discurso capitalista como vigente no contemporâneo, nós deparamos o limite imposto à prática com um sujeito desconectado, cuja queixa não remete a uma pergunta sobre o seu sofrimento. Trata-se do imperativo de solução e apaziguamento daquele que se encontra alojado na posição de vítima ou objeto. $\mathrm{O}$ analista, nesse contexto, também é tomado como mais um objeto a ser consumido e, em seguida, descartado.

Para a psicanálise, interessa permitir ao sujeito implicar-se em sua queixa, partindo do suposto de sua participação na criação e na manutenção do próprio sofrimento. A proposta, então, é que cada um possa construir um saber sobre o que lhe causa. Para tal, é preciso que se produza uma mudança de posição subjetiva que traga para o centro do tratamento o sintoma como algo a partir do qual um saber se advinha. Essa perspectiva em relação ao sintoma marca uma das especificidades da psicanálise na abordagem do malestar, pois vai na contramão do apagamento da divisão subjetiva.

Considerando a palavra como portadora de consequências, é possível enlaçar o sujeito em uma crença, a partir da sua fala. Isso porque a verdade tem estrutura de ficção, já que se constrói desde significantes. Assim, o analista convida o sujeito a interessar-se pela verdade de seu sofrimento, de seu sintoma. É nesse contexto que se insere a transferência, em sua modalidade de amor, em suas relaçôes com o saber.

Considerando a experiência analítica como um dispositivo discursivo, entendemos que o sujeito, primeiro alojado no discurso capitalista, faz uma virada para o discurso do mestre pela via do amor de transferência. Tal estratégia abre espaço para que os giros discursivos aconteçam e que o sujeito possa advir no discurso da histeria. Discurso que se caracteriza por evidenciar o sintoma e trazer para o centro do tratamento a dimensão de sujeito barrado.

O tratamento analítico abre espaço para que essa falha se evidencie, fazendo emergir o sujeito dividido, sujeito do inconsciente. Nesse momento, o analisante questionará seu sintoma, deixando-se intrigar pelo seu sofrimento. O endereçamento de uma pergunta a quem o sujeito supõe um saber, ao não ser respondida, mas devolvida, promove a histerização do discurso, entrada do sujeito no discurso da histérica. Nesse momento, ocorre a instalação da experiência propriamente dita.

Pensamos, portanto, ser possível a transformação, por meio do amor de transferência, de uma demanda de alívio para uma demanda de saber. Essa mudança configura-se dentro de uma experiência de fala, que possibilita que o sujeito transforme sua relação com esta. No lugar de reclamar e posicionar- 
se como vítima do outro, o sujeito passa a se questionar sobre o que quer, abrindo espaço para que se fale sobre o seu desejo. Desse modo, as entrevistas preliminares devem ser tomadas como um tempo de trabalho que permitirá a instauração de uma nova dimensão no tratamento. Esse período de retificação subjetiva possibilita ao sujeito vislumbrar sua posição ativa na instauração e manutenção do mal-estar do qual padece.

\section{Referências}

Bassols, M. Una politica del síntoma: llevar el sujeto hasta su división más próxima. In: Una politica del síntoma. Disponível em: <http://www.elpdebates.com/el-slpe/txmb.htm> (Acessado em: 26 set. 2004).

Bauman, Z. (2003). Amor líquido: sobre a fragilidade dos laços humanos. Rio de Janeiro: Jorge Zahar.

Besset, V. L. (2004). A política e o dizer do analista. Latusa, 9, 63-68.

Breuer, J. \& Freud, S. (1893-1895 [1986]). Estudios sobre la histeria. In: Breuer, J. \& Freud, S. Psicoterapia de la histeria. (v. 2, p. 1-316). Buenos Aires: Amorrortu editores. (texto original publicado em 1895)

Brodsky, G. (2000). Las enfermedades del sujeto supuesto saber. In: Colección Orientación Lacaniana - EOL. Acerca del sujeto supuesto saber. (p. 89-95). Buenos Aires: Paidós.

Brousse, M.-H. (2003). Os quatro pontos cardinais da psicanálise aplicada. Curinga: como a psicanálise cura. (p. 68-77). Belo Horizonte: Escola Brasileira de Psicanálise, 19.

Freud, S. (1986). El malestar en la cultura. (v. 21, p. 57-140). Buenos Aires: Amorrortu editores. (texto original publicado em 1930)

Horne, B. (2007). Os nomes do amor. Opção Lacaniana, 48, 43-67, mar.

Jorge, M. A. C. (2002). Discurso e liame social: apontamentos sobre a teoria lacaniana dos quatro discursos. In: Rinaldi, D. \& Jorge, M. A. C. (orgs.). Saber, verdade e gozo. Leituras de O Seminário, livro 17, de Jacques Lacan. (p. 17-32). Rio de Janeiro: Rios Ambiciosos.

Lacan, J. (1975). La troisième. Intervention au Congrès de Rome (1974). Lettres de l'École freudienne, 16, 177-203. 
Lacan, J. (1973 [2003]). Introdução à edição alemã de um primeiro volume dos Escritos. In: Lacan, J. Outros escritos. (p. 550-556). Rio de Janeiro: Jorge Zahar.

Lacan, J. (1967 [2003]). Proposição de 9 de outubro de 1967 sobre o Psicanalista da Escola. In: Lacan, J. Outros escritos. (p. 248-264). Rio de Janeiro: Jorge Zahar.

Lacan, J. (1972-1973 [1985]). O Seminário, livro 20: mais, ainda. Rio de Janeiro: Jorge Zahar.

Lacan, J. (1971-1972). Lição 3 de 6 jan. 1972. In: Lacan, J. O Seminário, livro 19: ou pire... inédito.

Lacan, J. (1969-1970 [1992]). O Seminário, livro 17: o avesso da psicanálise. Rio de Janeiro: Jorge Zahar.

Lacan, J. (1960-1961 [1992]). O Seminário, livro 8: a transferência. Rio de Janeiro: Jorge Zahar.

Lacan, J. (1953 [1998]). Função e campo da fala e da linguagem em psicanálise In: Lacan, J. Escritos. (p. 238-324). Rio de Janeiro: Jorge Zahar.

Lipovetsky, G. (2004). Os tempos hipermodernos. São Paulo: Barcarolla.

Miller, J.-A. \& Milner, J.-C. (2006). Você quer mesmo ser avaliado? Entrevistas sobre uma máquina de impostura. São Paulo: Manole.

Miller, J-A. (2007). O inconsciente real. Opção Lacaniana [on-line]. 2007, 4 (abril). Disponível em: <http://www.opcaolacaniana.com.br/index.asp>. (Acessado em: 15 maio 2007).

Miller, J-A. (2005). Uma Fantasia. Opção Lacaniana, 42, 7-18.

Miller, J-A. (2004). A era do homem sem qualidades. Opção Lacaniana [online]. 2004, 1. Disponível em: <http://www.opcaolacaniana.com.br/n1/texto. asp>. (Acessado em: 4 maio 2007).

Miller, J-A. (1987 [1997]). O Método Psicanalítico. In: Miller, J-A. Lacan elucidado: palestras no Brasil. (p. 221-284). Rio de Janeiro: Jorge Zahar.

Palomera, V. Responder al síntoma o responder del síntoma? In: Una política del sintoma. Disponível em: <http://www.elp-debates.com/el-slpe/txmb. htm>. (Acessado em: 26 set. 2004). 
Solano-Suarez, E. (2005). Os poderes do amor. Latusa, 10, 51-60.

Solano-Suarez, E. (2006). Entrevista concedida a Miriah Fernandes em 28 ago. 2006. Boletim n. 3 do XVI Encontro Brasileiro do Campo Freudiano "Nomes do Amor" [on-line]. 2006. Disponível em: <www.ebp.org> (Acessado em: 30 set. 2006).

\section{Gráficos}

\section{Matema I}

Discurso do Mestre

$\frac{\mathrm{S} 1}{\$} \rightarrow \frac{\mathrm{S} 2}{\mathrm{a}}$

Discurso do Psicanalista
Discurso da Histérica

$\frac{\$}{\mathrm{a}} \rightarrow \frac{\mathrm{S} 1}{\mathrm{~S} 2}$

Discurso do Universitário

$\frac{\mathrm{S} 2}{\mathrm{~S} 1} \rightarrow \frac{\mathrm{a}}{\$}$

\section{Matema II}

Discurso do Capitalista ${ }^{4}$

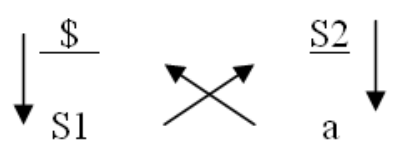

Outro

- outro

produção

${ }^{4}$ Lacan, J., 1972, Conferência de Milāo. 


\section{Matema III}

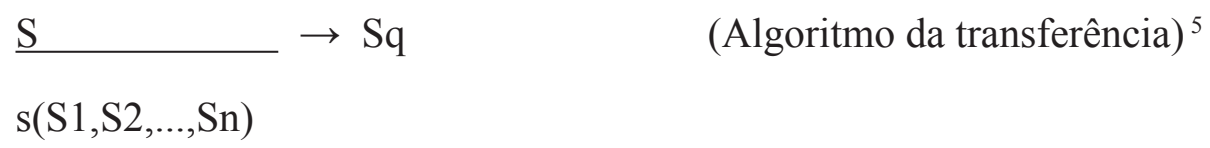

\section{Esquema I}

Efeito de retroação

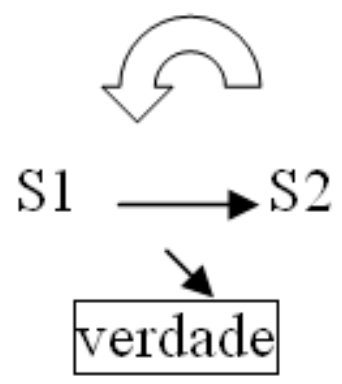

Esquema II

Discurso Capitalista

Discurso do Mestre ${ }^{6}$
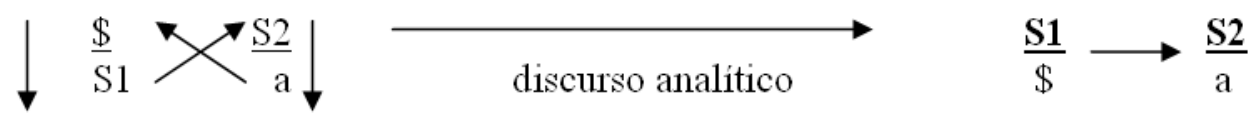

\section{Esquema IV}

\footnotetext{
${ }^{5}$ Para mais detalhes, veja Lacan, J., 1967 [2003].

${ }^{6}$ Grifo nosso na primeira parte do binômio.
} 